\title{
Spinal malignant triton tumor in a patient with neurofibromatosis type 1
}

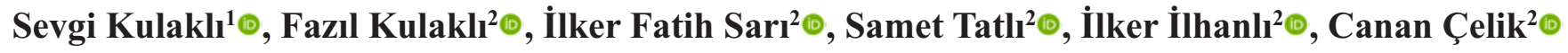 \\ ${ }^{1}$ Department of Dermatology, Giresun University School of Medicine, Prof. Dr. Illhan Özdemir Training and Research Hospital, Giresun, \\ Turkey \\ ${ }^{2}$ Department of Physical Medicine and Rehabilitation, Giresun University School of Medicine, Prof. Dr. Illhan Özdemir Training and \\ Research Hospital, Giresun, Turkey
}

DOI: $10.18621 /$ eurj.464297

Received: September 26, 2018; Accepted: February 26, 2019; Published Online: March 21, 2019

\section{Dear Editor,}

T eurofibromatosis type 1 (NF1) is an autosomal dominant disorder with $100 \%$ penetrance that affects approximately 1 in 3500 people [1]. Malignant triton tumor (MTT) is a rare malignant peripheral nerve sheath tumor (MPNST) with rhabdomyoblastic differentiation. Malignant triton tumor is commonly seen in the head, neck, extremities, and trunk and only $2-3 \%$ of all MPNSTs arise from the spinal nerves. MTT has an aggressive biological behavior, being $50 \%$ of cases associated with NF1 and has worse prognosis than MPNST without rhabdomyoblastic differentiation $[2,3]$. In this study, we aimed to present a

patient with MTT. Although MTT is an aggressive tumor, it is possible to detect it asymptomatically and incidentally, so we think that, doctors should be careful in this regard, especially in patients with NF1.

A 59-year-old male patient with neurofibromatosis, was admitted to our inpatient clinic with weakness in both lower extremities. One month ago, the patient falled down from a high place and weakness in lower extremities started after this fall. Thoracal 10 vertebra pathologic fracture and significant spinal cord pressure were detected after the evaluations and the patient was operated urgently. During the operation, the surgeon saw a mass ingrained in the spinal cord and he excited this mass and sent it to pathology department. The mental function of the patient was normal. However, the mental function has begun to deteriorate after a traffic accident. His sister stated that the same illness was also in her, her mother and sister. The general condition and consciousness of the patient was good but cooperation and orientation were not enough. Multiple neurofibromas were observed on the skin (Figure 1). Neurofibromas began to form in the skin of the patient in childhood and he was diagnosed with neurofibromatosis. Cranial nerves and upper extremity examination were normal. Range of motions of lower extremity joints were normal. Proximal and distal muscle strength of right lower extremity was $4 / 5$, left lower extremity was $1 / 5$. Sensory examination failed due to lack of cooperation. Deep tendon reflexes were normoactive and no pathological reflex was detected. The patient was diagnosed with incomplete paraplegia and the rehabilitation program was started. During the rehabilitation program, it was learned that the pathology result of the patient was MTT. The pathology result was evaluated by oncology unit and it was decided that the patient should continue the treatment in the

Address for correspondence: Fazll Kulakll, MD., Assistant Professor, Giresun University School of Medicine, Prof. Dr. Ilhan Özdemir Training and Research Hospital, Department of Physical Medicine and Rehabilitation, Giresun, Turkey 


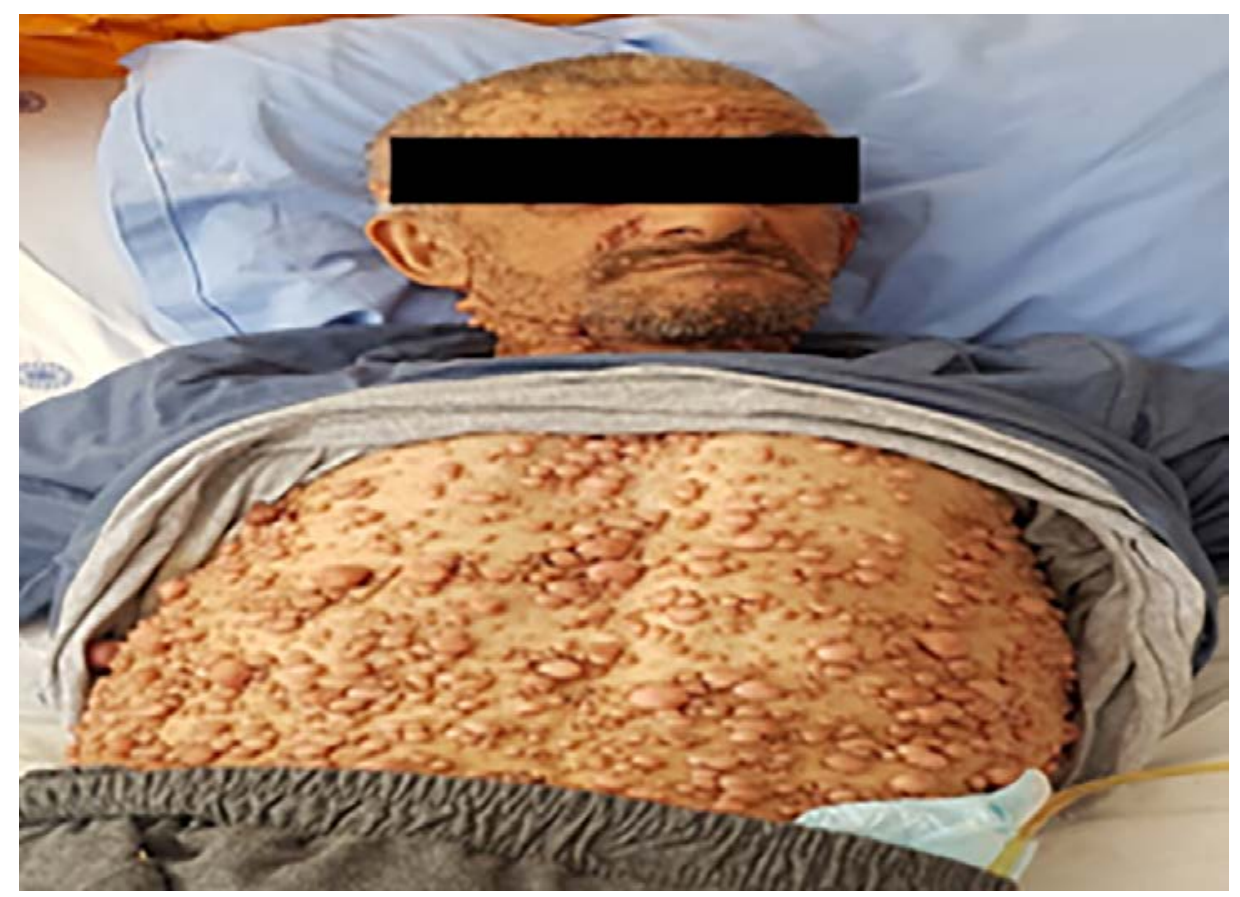

Figure 1. Multiple neurofibromas images

oncology unit.

Neurofibromatosis type 1 is characterized by cutaneous neurofibromas, café-au-lait spots, skeletal dysplasias, Lisch nodules, and sometimes malignant tumors [5]. Patients with NF1 at a significantly higher risk for benign and malignant tumors. MTT is an aggressive and rare MPNST with rhabdomyoblastic differentiation. MTT is commonly seen in the head, neck, extremities, and trunk and only $2-3 \%$ of all MPNSTs arise from the spinal nerves. In our case, MTT arised from the spinal nerve. In a review of 124 cases of MTT reported from 1973 to $2010,38 \%$ of patients had $\mathrm{NF} 1$, and the median age at diagnosis was 33 years [4]. Patients with NF1 have a larger tumor size and worse disease outcomes than patients with sporadic disease. The 5 -year specific survival rate is $54 \%$ to $75 \%$ in MTT patients with NF1 [6]. Patients may present with enlarging mass. It may cause pain and neurological symptoms such as paraestesia, motor weakness and radicular pain $[3,6]$. Although MTT is an aggressive and symptomatic tumour in patients with NF1, our patient was asymptomatic and the tumor was detected incidentally unlike other cases in the literature. Depending on the location of mass, complete resection is the primary treatment method of MTT [7]. Radiotherapy is the other treatment that can be used when necessary [8]. Although the use of chemotherapy in
MPNST is not clear, its use in therapy has been accepted [9]. In conclusion, patients with neurofibromatosis generally have a high risk of tumors. MTT is an agressive and rare tumor which is more common in patients with neurofibromatosis. Unlike other cases in the literature, MTT clinic was asymptomatic in our patient, it was detected incidentally and it arised from spinal nerve which was seen very rarely. Even if the patients are asymptomatic, physicians should be careful in terms of MTT especially in patients with NF1.

\section{Authorship declaration}

All authors listed meet the authorship criteria according to the latest guidelines of the International Committee of Medical Journal Editors, and all authors are in agreement with the manuscript

\section{Informed consent}

Written informed consent was obtained from the patient for publication of this case report and any accompanying images.

\section{Conflict of interest}

The authors declared that there are no potential conflicts of interest with respect to the research, authorship, and/or publication of this article. 


\section{REFERENCES}

[1] Jouhilahti EM, Peltonen S, Heape AM, Peltonen J. The pathoetiology of neurofibromatosis 1. Am J Pathol 2011;178:1932-9.

[2] Engel EE, Brassesco MS, Valera ET, Barbosa MHN,Yamashita MEAS, Scrideli CA, et al. Clinico-genetic aspects of a pediatric non-neurofibromatosis type 1 malignant triton tumor with loss of chromosome X. Pediatr Blood Cancer 2012;59:1320-3.

[3] Kamran SC, Howard SA, Shinagare AB, Krajewski KM. Malignant peripheral nerve sheath tumors: prognostic impact of rhabdomyoblastic differentiation (malignant triton tumors), neurofibromatosis 1 status and location. EJSO 2013;39:46-52.

[4] McConnell YJ, Giacomantonio CA. Malignant triton tumors-complete surgical resection and adjuvant radiotherapy associated with improved survival. J Surg Oncol 2012;106:51-6.

[5] Lee MJ, Stephenson DA. Recent developments in neurofibromatosis type 1. Curr Opin Neurol 2007;20:135-41.

[6] Stucky CC, Johnson KN, Gray RJ, Pockaj BA, Ocal IT, Rose PS, et al. Malignant peripheral nerve sheath tumors (MPNST): the Mayo Clinic experience. Ann Surg Oncol 2012;19:878-85.

[7] Grobmyer SR, Reith JD, Shahlaee A, Bush CH, Hochwald SN. Malignant peripheral nerve sheath tumor: molecular pathogenesis and current management considerations. J Surg Oncol 2008;97:340-9.

[8] Ferner RE, Gutmann DG. International consensus statement on malignant peripheral nerve sheath tumors in neurofibromatosis 1. Cancer Res 2002;62:1573-7.

[9] Moretti VM, Crawford EA, Staddon AP, Lackman RD, Ogilvie CM.. Early outcomes for malignant peripheral nerve sheath tumor treated with chemotherapy. Am J Clin Oncol 2011;34:417-21. 